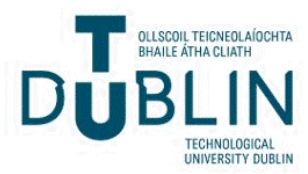

Technological University Dublin ARROW@TU Dublin

2013-1

\section{Dual-band Omnidirectional Circularly Polarized Antenna}

\author{
Adam Narbudowicz \\ Technological University Dublin \\ Xiulong Bao \\ Technological University Dublin, xiulong.bao@tudublin.ie \\ Max Ammann \\ Technological University Dublin, max.ammann@tudublin.ie
}

Follow this and additional works at: https://arrow.tudublin.ie/ahfrcart

Part of the Systems and Communications Commons

\section{Recommended Citation}

Narbudowicz, A., Bao, X. L., \& Ammann, M. J. (2013) Dual-band Omnidirectional Circularly Polarized Antenna, IEEE Transactions on Antennas \& Propagation, vol. 61, issue 1, pp. 77-83, 01/2013. doi:10.1109/ APMC.2012.6421505

This Article is brought to you for free and open access by the Antenna \& High Frequency Research Centre at ARROW@TU Dublin. It has been accepted for inclusion in Articles by an authorized administrator of ARROW@TU

Dublin. For more information, please contact

arrow.admin@tudublin.ie, aisling.coyne@tudublin.ie, gerard.connolly@tudublin.ie.

Funder: SFI

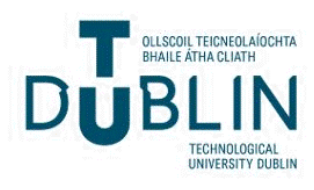




\title{
Dual-band Omnidirectional Circularly Polarized Antenna
}

\author{
Adam Narbudowicz, Student Member, IEEE, Xiu Long Bao, Senior Member, IEEE, and Max J. \\ Ammann, Senior Member, IEEE
}

\begin{abstract}
A dual-band omnidirectional circularly polarized antenna is proposed. The antenna comprises back-to-back microstrip patches fed by a coplanar waveguide. A very low frequency ratio of 1.182 has been achieved, which can be easily tuned by adjusting four lumped capacitors incorporated into the antenna. An analysis of the omnidirectional circular polarization mechanism as well the dual band operation is provided and confirmed by numerical and experimental data. Key parameters to tune the resonant frequencies and the axial ratio have been identified. The prototype antenna provides omnidirectional circular polarization in one plane with cross polar isolation better than $12 \mathrm{~dB}$ for both frequency bands.
\end{abstract}

Index Terms-Aperture coupled antennas, Circular Polarization, Microstrip antennas, Multifrequency antennas.

\section{INTRODUCTION}

$\mathrm{C}$ IRCULARLY POLARISED (CP) antennas have gained much attention due to their improved immunity to multipath distortion and polarization mismatch losses including those caused by Faraday rotation. These properties are desirable for satellite communications, WLAN and RFID systems. However the number of compact CP antennas with omnidirectional patterns is still very small. These antennas are needed for multi-user communication in indoor environments with many scatters (e.g. RFID or WLAN systems). In satellite communication, where one traditionally expects the beam to be directed towards the sky, the orientation of the antenna cannot be a priori determined for many applications, making omnidirectional antennas desirable. Moreover, many modern systems require dual-band operation with relatively low frequency ratios (i.e. the ratio between GPS L1 and L2 bands is 1.28; between L1 and Galileo E6, it is 1.232), which introduces additional complexity to the design.

To the best of our knowledge, there are no works in the open literature reporting dual-band omnidirectional CP antennas. The first approach to provide omnidirectional $\mathrm{CP}$ (for single frequency) involved an array of radiating elements, located around a common centre [1]-[4]. These solutions are somewhat large and more complex to manufacture than planar

Manuscript received September 9, 2011. Revised June $13^{\text {th }}$ 2012. This work was supported by the Science Foundation Ireland under Grant Number 09/SIRG/I1644.

A. Narbudowicz, X. L. Bao and M. J. Ammann are with the Antenna \& High Frequency Research Centre, Dublin Institute of Technology, Dublin 8, Ireland (phone: +353-1402-4905; fax: +353-1402-4690; e-mail: max.ammann @ dit.ie). structures. Attempts to reduce the number of radiators degraded the performance, with shouldering and dipping in the radiation pattern [2], [3]. A lower profile antenna was proposed in [5], where omnidirectionality was achieved by superposition of four horizontally polarized stubs and a vertically polarized mushroom structure.

There is very little reported work introducing omnidirectional CP behavior using planar structures. The first one employs epsilon negative material and its zeroth order resonance to replace a mushroom in [5] by a completely planar structure [6]. It exhibits good omnidirectional axialratio (AR), however the use of five combined elements and zeroth order resonance makes it difficult to modify the antenna for dual band operation.

Another paper introduces the basic concept of using backto-back coupled patches [7]. The AR in the plane of omnidirectionality for the planar structure is kept within a $4 \mathrm{~dB}$ limit and the $\mathrm{S}_{11}$ is $-11.19 \mathrm{~dB}$ for the $\mathrm{CP}$ frequency. There is however around $6 \mathrm{~dB}$ variation in the $\mathrm{CP}$ radiation pattern and no gain value reported.

Many techniques have been proposed to implement dualfrequency patch antennas for unidirectional $\mathrm{CP}$, including stacked patches [8], dual-negative materials [9], slots cut in the patch [10]-[12] or complex annual-ring structures [13].

From the above-mentioned patch structures, the slot loaded rectangular patch was chosen for our design due to its simplicity and relative compactness (compared to the stacked patch). Slots can be used to perturb the current distribution, shifting the higher modes down in frequency and modifying their radiation pattern to be broadside. Typically there is a slot along each radiating edge of the antenna [10], [12]. Such configuration employs a third resonant mode $\left(\mathrm{TM}_{300}\right)$, generating an unwanted $\mathrm{TM}_{200}$ mode that needs to be suppressed. As typical $\mathrm{CP}$ patch antennas employ two orthogonal modes, a total of four slots would be required using this technique.

In this paper the first dual-frequency antenna with omnidirectional performance is proposed. The omnidirectional right-handed CP is achieved by employing back-to-back coupled patches. The use of a novel feed, a conducting strip connected between patches and a reduced ground plane size allows better impedance matching and reduced overall size, compared to [7]. Slots with capacitive loading provide dualband operation, however in contrast to previous work, only two slots are used in each patch. This configuration supports $\mathrm{TM}_{200}$ (and respectively orthogonal $\mathrm{TM}_{020}$ ) mode rather than $\mathrm{TM}_{300}$, simplifying the design. 


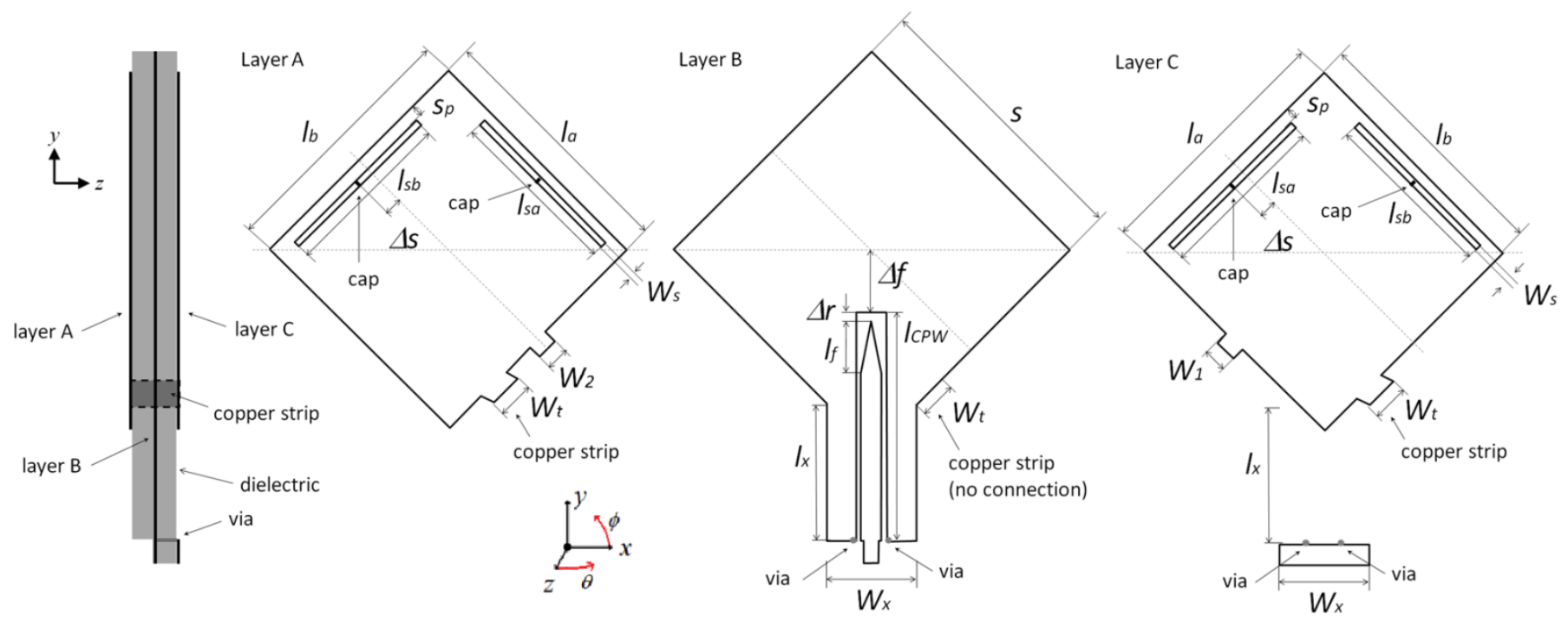

Fig. 1 Antenna geometry with key parameters across different layers of metallization (for convenience substrate thickness on the left is not to scale).

\section{ANTENNA DESIGN}

The antenna consists of two layers of substrate (Taconic ${ }^{\mathrm{TM}}$ RF 35, with $\varepsilon_{r}=3.47$ and height $h=1.54 \mathrm{~mm}$ ) placed between three layers of metallization. The inner metallization forms the ground plane and comprises the coplanar waveguide (CPW) feeding structure, whereas the outer ones form two patches in a back-to-back configuration. The patches are additionally connected together by a thin copper strip (see Fig. 1).

The radiators are electromagnetically-coupled to a $50 \Omega$ CPW (with slot $1 \mathrm{~mm}$ wide, central strip - $4.7 \mathrm{~mm}$ ) located along the diagonal of the patches. The end of the line is triangularly tapered to increase its impedance. The parameter $l_{C P W}$ was optimized to realize best matching (as the input resistance of the patch decreases towards its center). The use of the tapered transformer provides greater immunity to the slight difference in input impedance of the two resonant modes of the patch.

The other end of CPW transforms to a $5 \mathrm{~mm}$ long $50 \Omega$ microstrip line (with the ground planes connected by vias) connected to an SMA. The substrates are cut along the footprint of the ground plane.

There are two slots cut in each patch, with a $1.5 \mathrm{pF}$ lumped capacitor [14] connected across the centre. The slots are of slightly different lengths, which is one of the $\mathrm{CP}$ perturbation mechanisms.

The structure was manufactured using LPKF Proto Mat milling robot. The ground plane (layer B) was milled on both layers of substrate, providing better symmetry between the patches. For precise alignment, a row of holes along the antenna perimeter was used

The antenna was simulated using the CST MWS Frequency-Domain Solver. The parameter values are: $l_{a}=57 \mathrm{~mm} ; \quad l_{b}=57.1 \mathrm{~mm} ; \quad s_{p}=2.25 \mathrm{~mm} ; \quad l_{s b}=36.8 \mathrm{~mm} ;$ $l_{s a}=35.8 \mathrm{~mm} ; \quad W_{s}=1.5 \mathrm{~mm} ; \Delta s=3 \mathrm{~mm} ; \quad W_{t}=5.0 \mathrm{~mm} ;$ $\Delta_{f}=14.0 \mathrm{~mm} ; \quad \Delta_{r}=2.0 \mathrm{~mm} ; \quad l_{f}=12.0 \mathrm{~mm} ; \quad l_{c p w}=50.8 \mathrm{~mm} ;$ $W_{X}=20.0 \mathrm{~mm} ; l_{X}=29.7 \mathrm{~mm} ; s=64 \mathrm{~mm}$. The width of tuning stubs are $W_{1}=9.0 \mathrm{~mm}$ for layer $\mathrm{C}$ side and $W_{2}=6.0 \mathrm{~mm}$ for layer A.

\section{Simulation AND MEASUREMENTS}

The antenna radiates right handed circular polarization (RHCP) for both the upper and lower frequencies of $1.565 \mathrm{GHz}\left(\mathrm{S}_{11}=-22.8 \mathrm{~dB}\right)$ and $1.329 \mathrm{GHz}\left(\mathrm{S}_{11}=-11.7 \mathrm{~dB}\right)$ respectively, with a frequency ratio of 1.178 . This is smaller than presented in [13], [12] and can be easily retuned to fit into the E5a, E5b, L2 or even the E6 band. The simulated AR in the $x z$-plane varies from $1.2 \mathrm{~dB}$ to $2.9 \mathrm{~dB}$ for the lower band and from $2.5 \mathrm{~dB}$ to $5 \mathrm{~dB}$ for the upper band. The antenna was prototyped and tested. Fig. 2 shows good $S_{11}$ agreement between simulation and measurement. The simulated radiation efficiency is $62 \%$ for the lower band and $50 \%$ for the upper band.

The measured $S_{11}$ exhibits a good dual-band response, with no additional modes between bands (as expected by employing only a single slot per mode). The measured AR is shown in Fig 3 and remains between $0.4 \mathrm{~dB}$ to $3.8 \mathrm{~dB}$ for the lower band and is in reasonable agreement with the simulation. For the higher band the $\mathrm{AR}$ varies $0.6 \mathrm{~dB}$ to $4.4 \mathrm{~dB}$. Although it is higher than a $3 \mathrm{~dB}$ limit popularly accepted for unidirectional $\mathrm{CP}$ antennas, it still provides better than $12 \mathrm{~dB}$ isolation between RHCP and LHCP over the full omnidirectional plane. Fig. 4 depicts the AR as a function of both angle and frequency. The measured frequency ratio is 1.182. A clear omnidirectional and dual-band pattern can be seen. The radiation patterns are shown in Figs. 5-6 for the $z x$ (omnidirectional) plane and in Figs 7-8 for the $z y$ plane. The RHCP gain ranges from $-0.7 \mathrm{dBic}$ to $-4.5 \mathrm{dBic}$ for the upper band and from $-0.7 \mathrm{dBic}$ to $-4 \mathrm{dBic}$ for the lower band. The gain for the upper frequency is in good agreement but for the lower band is up to $2 \mathrm{~dB}$ less than simulated. This is because of feeder cable effects due to the small ground plane. Additional simulations, which incorporated the feeder cable section as in [15] support this explanation, but are not shown for brevity. 


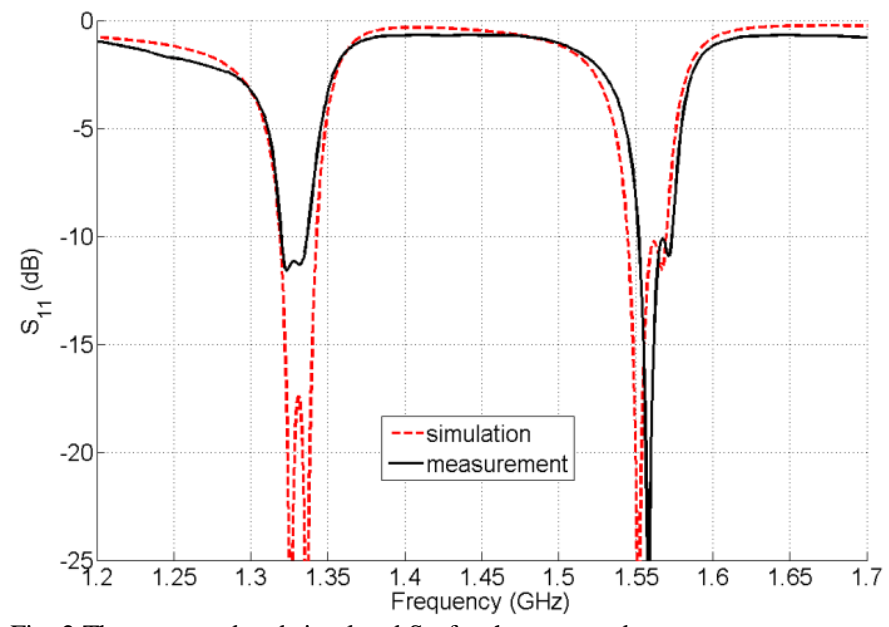

Fig. 2 The measured and simulated $S_{11}$ for the proposed antenna.

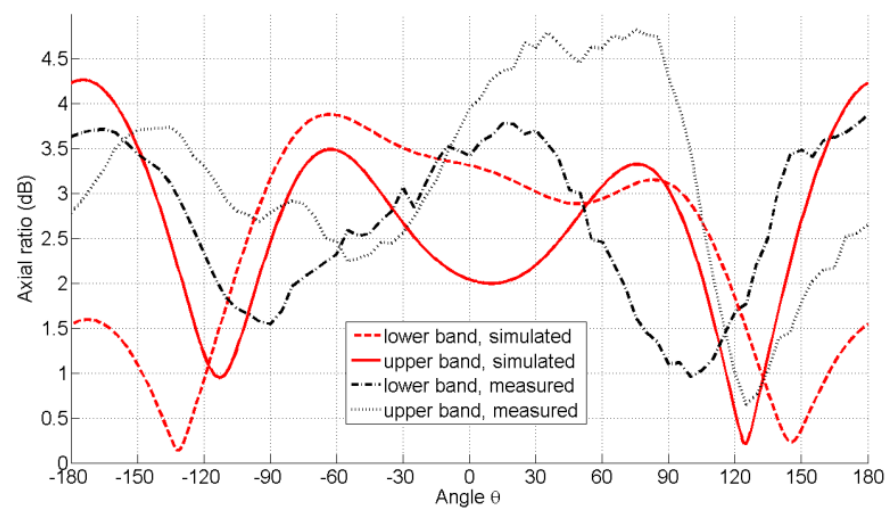

Fig. 3 The simulated and measured axial ratio for the lower and upper frequency.

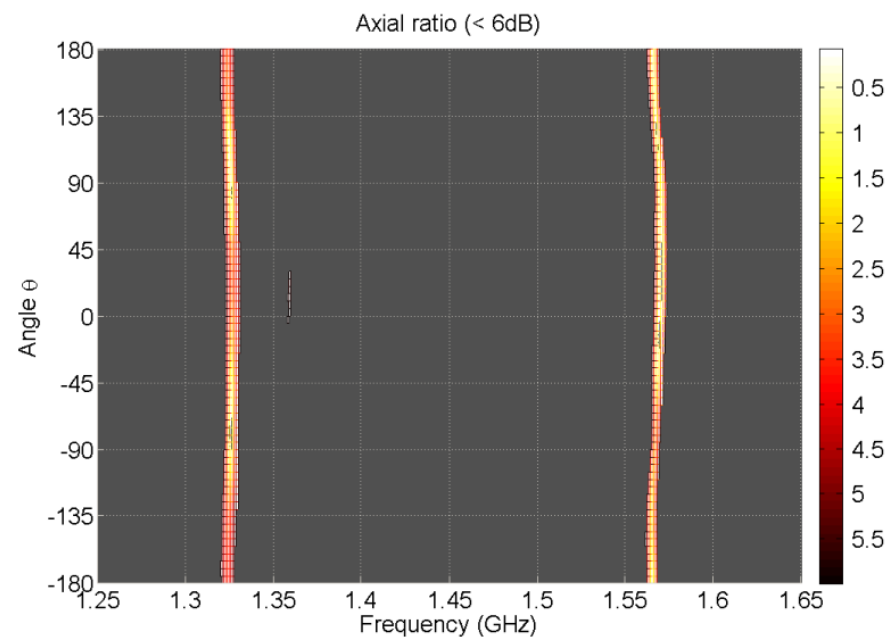

Fig. 4 The measured axial ratio as a function of angle and frequency. For convenience, values above $6 \mathrm{~dB}$ are denoted by the grey color. Optimum frequencies are $1.325 \mathrm{GHz}$ and $1.567 \mathrm{GHz}$.

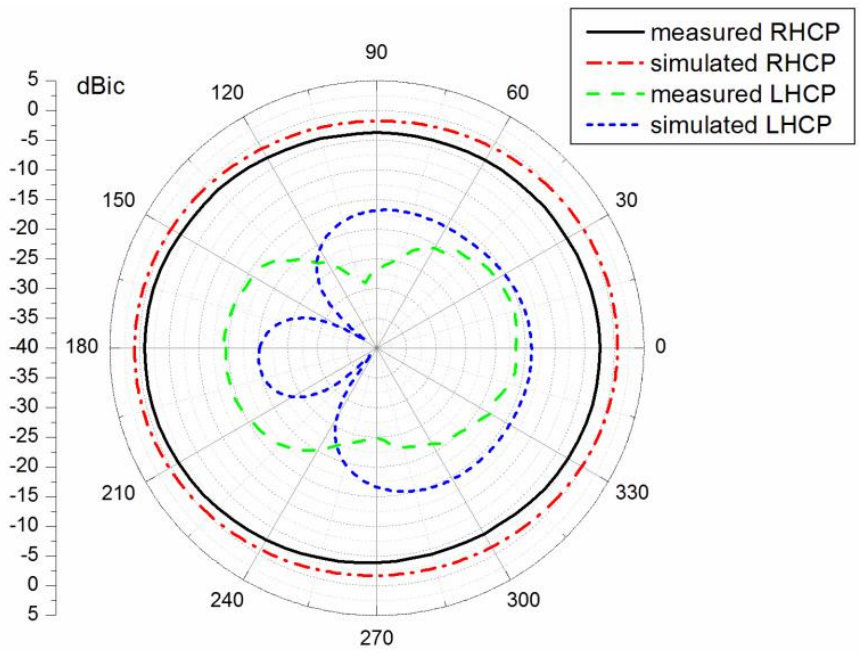

Fig. 5 The measured and simulated radiation patterns in the $z x$-plane $(\phi=0$ cut) for the lower band. Angle $\theta=0$ corresponds to the direction of $z$-axis.

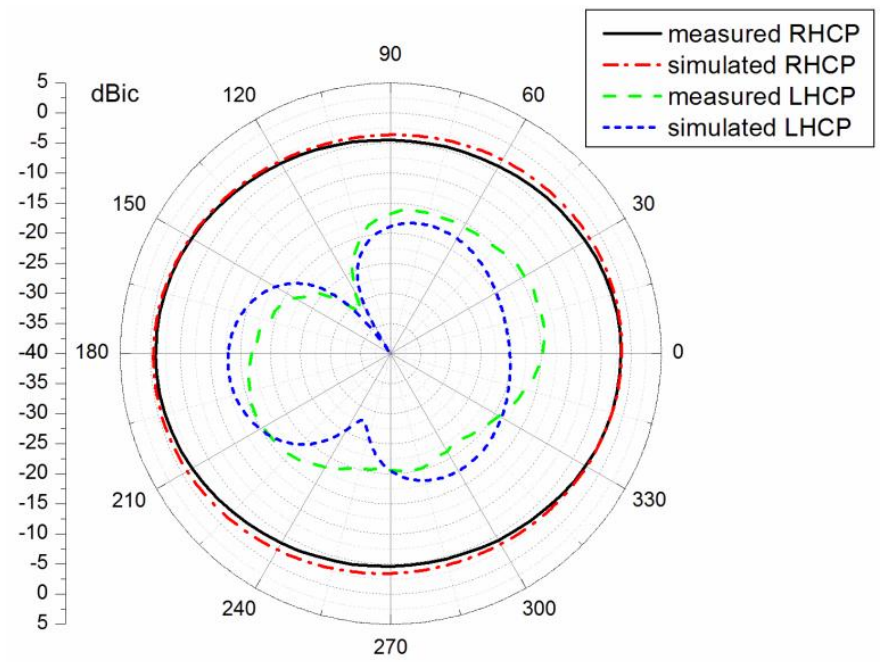

Fig. 6 The measured and simulated radiation patterns in the $z x$-plane $(\phi=0$ cut) for the upper band. Angle $\theta=0$ corresponds to the direction of $z$-axis.

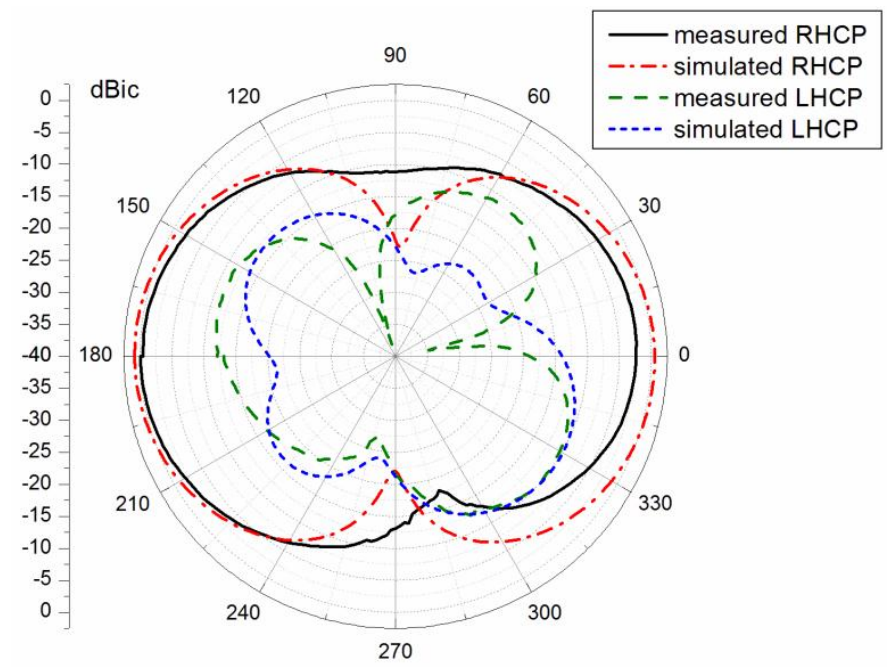

Fig. 7 The measured and simulated radiation patterns in the $z y$-plane $(\phi=90$ cut) for the lower band. Angle $\theta=0$ corresponds to the direction of $z$-axis. 


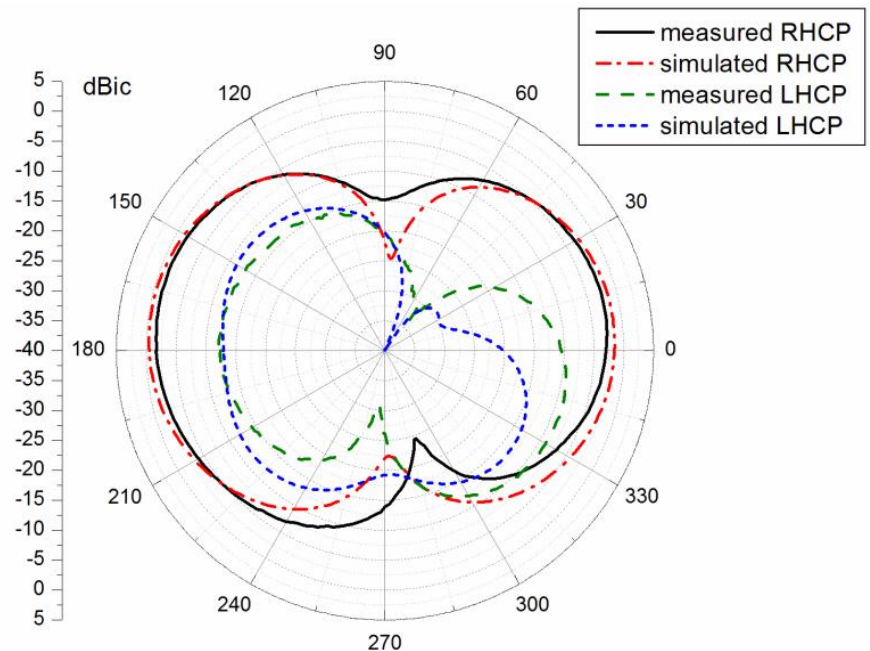

Fig. 8 The measured and simulated radiation patterns in the $z y$-plane $(\phi=90$ cut) for the upper band. Angle $\theta=0$ corresponds to the direction of $z$-axis.

\section{DESIGN PROCESS}

The overview of the design sequence used is as follows:

1) Calculate the initial lengths of the patch $\left(l_{a}\right.$ and $l_{b}$, which at this stage can be equal), which should be approximately one half of an electrical wavelength at the lower resonant frequency $\left(\mathrm{TM}_{100}\right.$ mode) for the given substrate.

2) Initially set the slot length $l_{s a}=l_{s b}=0.63 l_{a}$; the slot-toedge separation $s_{P}=0.04 l_{a}$ and the slot width $W_{S}$ $=0.026 l_{a}$. With these values, increased lumped element capacitance (within $1-2 \mathrm{pF}$ range) reduces the frequency ratio (FR). This property and a full-wave electromagnetic simulation was used to yield the desired FR. Note that the FR reduction factor may vary for different substrates.

3) The lumped capacitors should lower both resonant frequencies. Therefore additional adjustment is needed, by properly setting the patch size $\left(l_{a}\right.$ and $\left.l_{b}\right)$ and slot parameters $\left(l_{s a}, l_{s b}\right.$ and $\left.W_{s}\right)$.

4) The impedance match is adjusted by proper selection of parameters $s_{p}$ and $\Delta f$, as well as small variations in the ground plane size $S$.

5) The $\mathrm{AR}$ at both frequencies is tuned to achieve omnidirectional CP radiation. This requires adjustment of stub widths $W_{1}$ and $W_{2}$, as well as introducing a small difference between slot lengths $l_{s a}$ and $l_{s b}$, and between the patch dimensions $l_{a}$ and $l_{b}$. (Note that where the symmetry is compromised an independent adjustment might be necessary).

The following sections provide a more in-depth description of the design steps.

\section{A. Dual-band Operation}

In [10] a simple model was proposed for prediction of the upper resonant frequency. The model was given for a linearly polarized antenna with two slots without capacitors. It approximates the area around a slot as a thin microwave resonating stub (as shown in Fig. 9). The proposed antenna is significantly different to [10] and [12], as it employs additional stubs, single slot per mode and a connection between both patches. Some coupling will exist for slots in close proximity, resulting in less accurate predictions [10]. To minimize this, the slots have been separated $(\Delta s=3 \mathrm{~mm})$. Despite these differences, the model is still useful to qualitatively demonstrate the operation principle of the proposed antenna.

The lower band is also influenced by the slots, as shown in Fig. 10. The resonant frequency decreases with increased slot length $l_{s b}$ and $l_{s a}$. For longer slots the $\mathrm{TM}_{100}$ and $\mathrm{TM}_{010}$ mode currents are more disturbed, resulting in poor matching.

The ratio between the two frequencies can be varied by changing the lumped capacitance. As can be seen in Fig. 11, greater capacitance values shift both operating bands downwards and also reduce the FR. To tune the antenna for the L1/L2 GPS band a capacitor of approximately $1 \mathrm{pF}$ should be used, which gives a FR of around 1.26. Table 1 provides some typical FR values for different values of ideal capacitors. As the FR is also dependant on the size and location of the slots all values in Table 1 are given for $l_{s b}=36.8 \mathrm{~mm}$ and $l_{s a}=35.8 \mathrm{~mm}$. Above a certain value there is no further decrease in FR, although both operating frequencies continue to decrease.

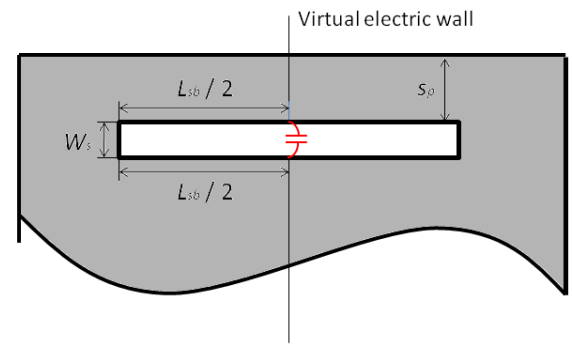

Fig. 9 The edge of the patch illustrating the resonating stub. The length of the stub is $\mathrm{W}_{\mathrm{s}}+2 * \mathrm{~L}_{\mathrm{sb}} / 2$.

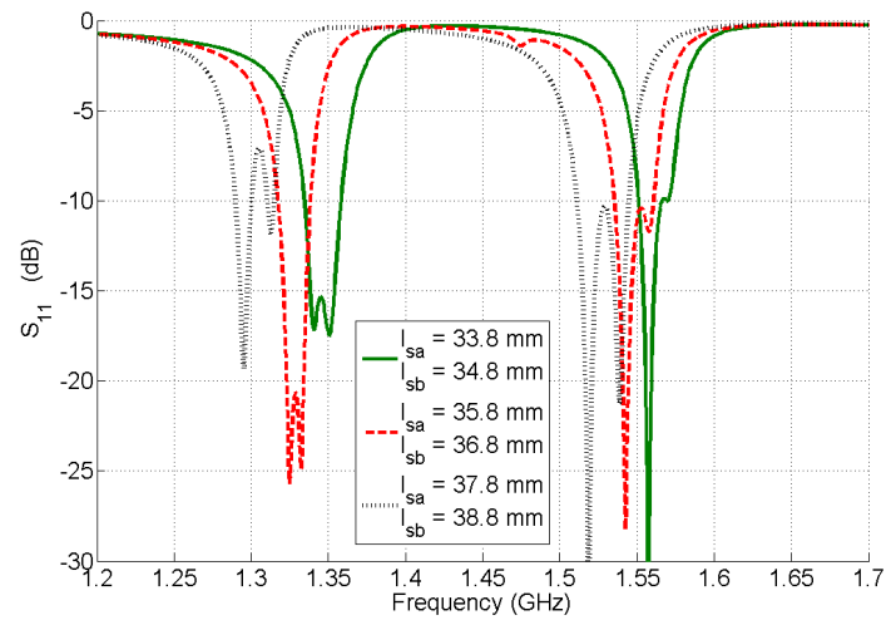

Fig. 10 The simulated $S_{11}$ for different slot lengths $\left(l_{s b}-l_{s a}=1 \mathrm{~mm}\right.$ for all configurations). 


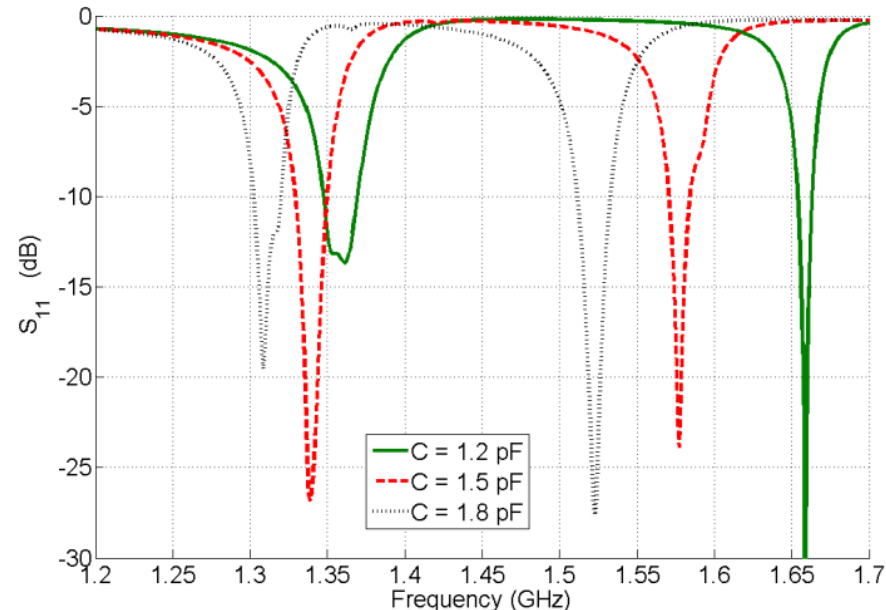

Fig. 11 The simulated $S_{11}$ for different capacitor values. The results were calculated with perfect capacitors, hence a slight difference with data presented in Fig. 2 .

TABLE I

FREQUENCY RATIOS FOR DIFFERENT CAPACITOR VALUES

\begin{tabular}{ccccc}
\hline \hline $\begin{array}{c}\text { Capacitor } \\
\text { value }(\mathrm{pF})\end{array}$ & $\begin{array}{c}\text { Lower } \\
\text { frequency } \\
(\mathrm{GHz})\end{array}$ & $\begin{array}{c}\text { Upper } \\
\text { frequency } \\
(\mathrm{GHz})\end{array}$ & $\begin{array}{c}\text { Simulated } \\
\text { frequency } \\
\text { ratio }\end{array}$ & $\begin{array}{c}\text { Measured } \\
\text { frequency } \\
\text { ratio }\end{array}$ \\
\hline 1.0 & 1.366 & 1.724 & 1.26 & 1.28 \\
1.2 & 1.357 & 1.660 & 1.223 & 1.207 \\
1.5 & 1.341 & 1.584 & 1.178 & 1.182 \\
1.8 & 1.314 & 1.523 & 1.159 & 1.153 \\
2.0 & 1.291 & 1.494 & 1.158 & 1.148 \\
\hline \hline
\end{tabular}

\section{B. Impedance Match}

The energy is coupled into the patches using proximity coupling. The CPW feed has some impact on the AR, because it requires slots to be cut in the ground plane [7]. To mitigate this (The CPW is placed - unlike in [7] - along a diagonal, therefore interacting with both orthogonal modes) the coupling end of the CPW was placed relatively close to the edge of the patch, where the input resistance is much higher. To overcome this problem the CPW was triangularly tapered. The impedance of the line increases along the taper and the input resistance of the patch decreases towards its centre. This technique ensures a good match, even when the input impedances for the lower and upper frequencies are different.

The size of the ground plane has been decreased in the proposed design. It was shown in [16] that such a reduction can lower the patch input resistance and slightly shift the operating frequency. An additional advantage is the reduced antenna footprint, but at the cost of reduced gain.

The distance $s_{p}$ between the slot and the patch edge is also critical for the impedance match. For the upper band we can employ the stub model, described in section IV. As seen in Fig. 9, the parameter $s_{p}$ defines the width of the stub, which impacts on the stub impedance. However the stub is only one part of the antenna and it should be noted, that by increasing only $s_{p}$ the unperturbed area in the middle of the patch is decreased, causing an increase in the operating frequency. For the lower band, the capacitor loaded slot increases the current path and decreases the operating frequency. A trade-off between the two bands is necessary, which may require an iterative design approach.

The two patches are connected together using a copper strip positioned near the feed point, ensuring equal phase patch currents, which is critical for omnidirectional operation. This feature improves robustness with respect to potential manufacturing asymmetries between the layers.

\section{Axial Ratio Adjustment}

Omnidirectional CP has been achieved employing two back-to-back patches, each radiating the same sense polarization. This means the patches are in rotational symmetry with respect to $y$-axis, as seen on Fig. 1 . The CP antennas which employ the almost-square patch method are known for being relatively narrowband, but have a wide beam pattern [17]. Thus the patches on layers A and C generate CP beams which are wide enough to overlap and hence produce an omnidirectional $\mathrm{CP}$ pattern. In reality small inaccuracies may affect the symmetry between the patches. To overcome this problem the values of $W_{1}$ and $W_{2}$ are different on each side.

The proposed design uses three independent parameters to control AR at both frequencies:

- $\quad$ an almost square geometry $\left(l_{b}>l_{a}\right)$

- $\quad$ an additional stub with variable width $\left(W_{l}\right.$ and $\left.W_{2}\right)$

- different slot lengths $\left(l_{s b}>l_{s a}\right)$

Other methods are used to generate $\mathrm{CP}$, including truncated corners [7], asymmetric slits [18], or additional slots [8]. Although only one perturbation technique is used in many dual-band antenna designs, the use of three independent techniques allows more independent control of the AR for each frequency band.

If the patch is prolonged along one edge (but without changing the position of the slot) it will shift the lower resonant frequency, however the upper band should remain almost unchanged. This can be explained by referring to the stub model in Fig. 9, since the slot remains unchanged, parameter $s_{b}$ increases. This influences the impedance of the stub, however its resonant frequency remains unchanged (apart from the contribution by varied effective permittivity, which is very small). This property is very useful while adjusting the AR for the lower band.

An additional stub protruding from the patch is commonly used for various CP designs, especially for circular patches. It introduces phase perturbation by shifting down the frequency of the lower orthogonal modes. Stub widths greater than the chosen $W_{1}$ and $W_{2}$ values could provide better AR but degrade the matching as seen in Fig. 12.

A small difference between the slot lengths has been used for $\mathrm{CP}$ generation in [12]. Fig. 13 shows the simulated $S_{11}$ for different values of $l_{s b}$. As $l_{s a}$ is kept constant, this parameter also controls the lower orthogonal mode. In general for $l_{s a}>l_{s b}$ LHCP is achieved (assuming no other perturbation elements). Typically the difference between slot lengths should be small, as the AR is heavily dependent on this parameter. Fig. 14 shows that even a small variation of $1 \mathrm{~mm}$ can strongly degrade the AR, as well as shift its optimum frequency (here by up to $6 \mathrm{MHz}$ ). 


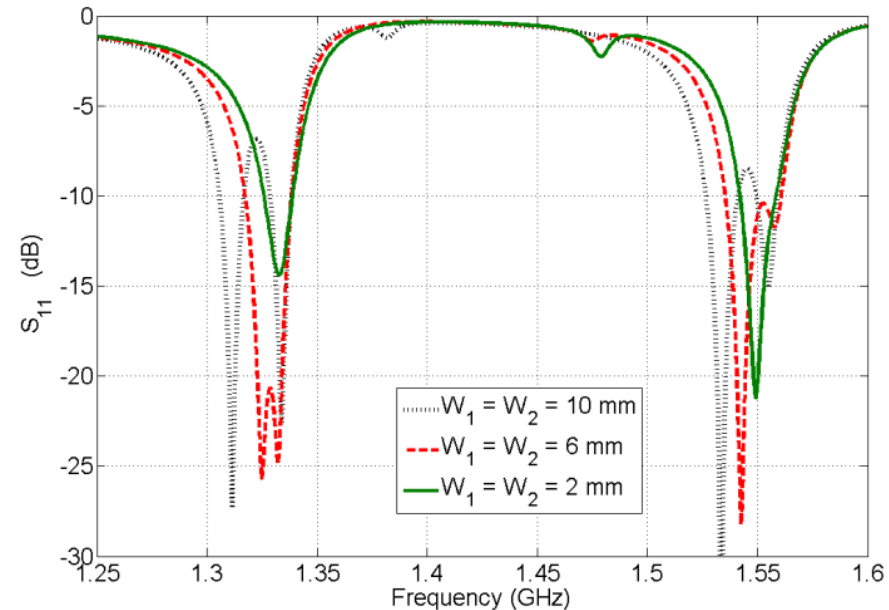

Fig. 12 The simulated $S_{11}$ for different stub widths $W_{l}$ and $W_{2}$

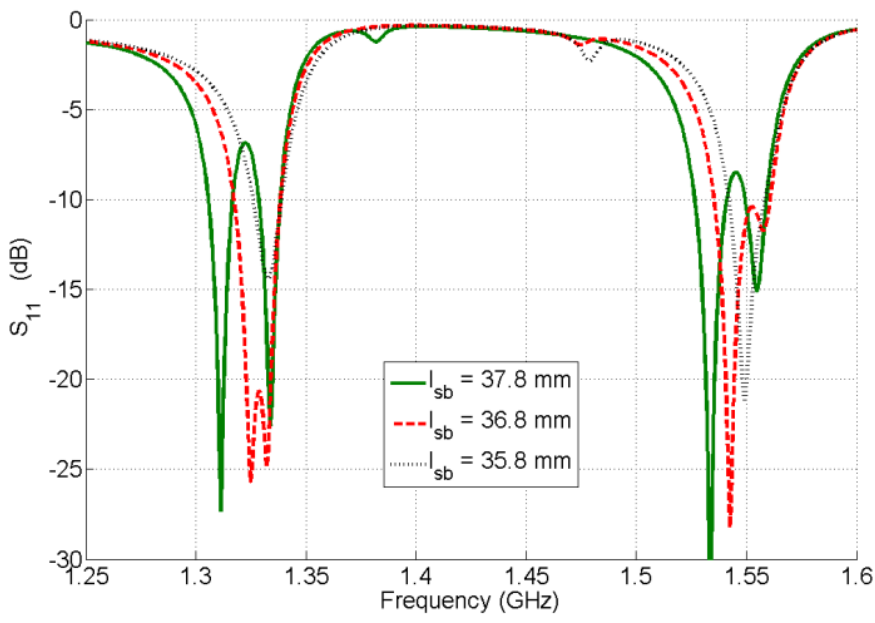

Fig. 13 The simulated $\mathrm{S}_{11}$ for different values of $l_{s b}\left(l_{s a}=35.8 \mathrm{~mm}\right)$.

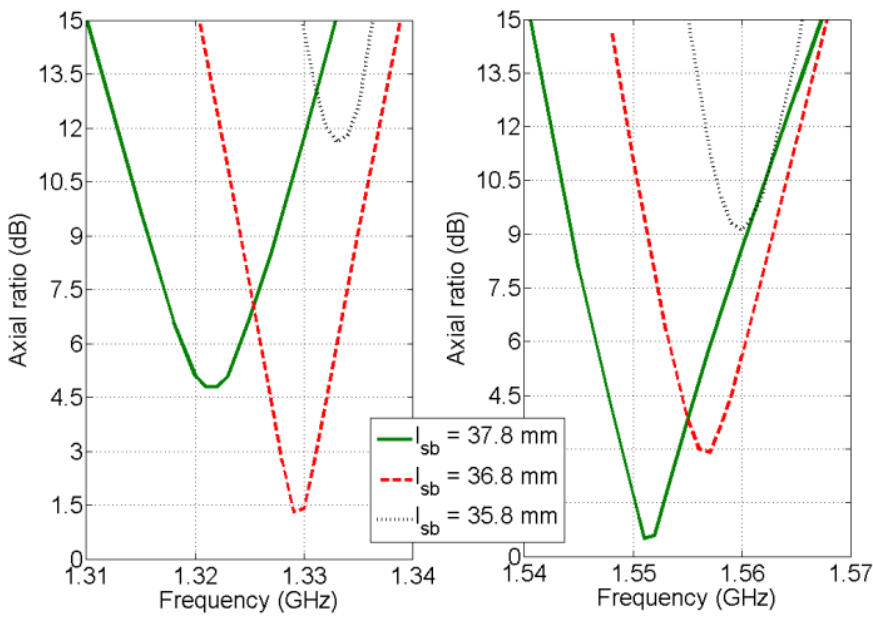

Fig. 14 The simulated axial ratio for different values of $l_{s b} .\left(l_{s a}=35.8 \mathrm{~mm}\right)$

\section{CONCLUSION}

A back-to-back microstrip patch antenna was shown to provide omnidirectional circular polarization over two frequency bands. The structure employs a small ground plane and lumped capacitor loaded slots which enable the generation of $\mathrm{TM}_{200}$ and $\mathrm{TM}_{020}$ modes. The prototype antenna has a low frequency ratio of 1.182, a good AR for both bands and more than $12 \mathrm{~dB}$ of cross-polar isolation.

\section{REFERENCES}

[1] D. I. Wu, "Omnidirectional circularly-polarized conformal microstrip array for telemetry applications," in Proc. Antennas and Propagation Society International Symposium, AP-S, Newport Beach, 1995, vol. 2, pp. 998-1001.

[2] Y. Xu, and C. Ruan, "A Novel Design of Circularly Polarized Omnidirectional Antenna for KaBand," in Proc. Global Symposium on Millimeter Waves, GSMM, Nanjing, 2008, pp. 378-379.

[3] J. D. Morrow, "Polarization-adjustable omnidirectional dipole array," IEEE Antennas and Wireless Propagation Letters, vol. 2, no. 1, pp. 223225, 2003.

[4] J. M. Fernandez, J. L. Masa-Campos, and M. Sierra-Perez, "Circularly polarized omnidirectional millimeter wave monopole with parasitic strip elements," Microwave and Optical Tech. Letters, vol. 49, no. 3, pp. 664668, Mar. 2007.

[5] F. R. Hsiao, and K. L. Wong, "Low-profile omnidirectional circularly polarized antenna for WLAN access points," Microwave and Optical Tech. Letters, vol. 46, no. 3, pp. 227-231, Aug. 2005.

[6] B.-C. Park, and Lee J.-H., "Omnidirectional Circularly Polarized Antenna Utilizing Zeroth-order Resonance of Epsilon Negative Transmission Line", IEEE Trans. on Antennas and Propagation, vol. 59, no. 7, pp. 2717-2721, Jul. 2011

[7] H. Iwasaki, and N. Chiba, "Circularly polarised back-to-back microstrip antenna with an omnidirectional pattern," IEE Proc. - Microwaves, Antennas and Propagation, vol. 146, no. 4, pp. 277-281, Aug. 1999.

[8] X. L. Bao, and M. J. Ammann, "Dual-frequency dual circularlypolarised patch antenna with wide beamwidth," Electronics Letters, vol. 44, no. 21, pp. 1233-1234, Oct. 2008.

[9] F. J. Herraiz-Martinez, and V. Gonzales-Posadas, "A dual band circularly polarized antenna based on a microstrip patch filled with lefthanded structures," in Proc. 2nd European Conf. on Antennas and Propagation, EuCAP, Edinburgh, 2007, pp. 1-6.

[10] S. Maci, G. B. Gentili, P. Piazzesi, and C. Salvador, "Dual-band slotloaded patch antenna," IEE Proc. - Microwaves, Antennas and Propagation, vol. 142, no. 3, pp. 225-232, Jun. 1995.

[11] Nasimuddin, Z. N. Chen and X. Qing, "Dual-Band Circularly Polarized S-Shaped Slotted Patch Antenna With a Small Frequency-Ratio", IEEE Trans. on Antennas and Propagation, vol. 58, no. 6, pp. 2112-2115, Jun. 2010.

[12] C.-Y. Huang, C.-W. Ling, and J.-S. Kuo, "Dual-band microstrip antenna using capacitive loading," IEE Proc. - Microwaves, Antennas and Propagation, vol. 150, no. 6, pp. 401-404, Dec. 2003.

[13] X.L. Bao, and M.J. Ammann, "Dual-Frequency Circularly-Polarized Patch Antenna With Compact Size and Small Frequency Ratio", IEEE Trans. on Antennas and Propagation, vol. 55, no. 7, pp. 2104-2107, Jul. 2007.

[14] MLCSoft, RF Capacitor Modelling Software, version 2.0, Johanson Technology Inc., Camarillo, CA, 2010.

[15] L. Liu, Y.F. Weng, S.W. Cheung, T.I Yuk, and L.J. Foged, "Modeling of cable for measurements of small monopole antennas," in Proc. Loughborough Antennas and Propagation Conference, LAPC, Loughborough, 2011.

[16] H. Iwasaki, "A back-to-back rectangular-patch antenna fed by a CPW," IEEE Trans. on Antennas and Propagation, vol. 46, no. 10, pp. 15271530, Oct. 1998.

[17] N. Herscovici, Z. Sipus and D. Bonefacic, "Circularly polarized singlefed wide-band microstrip patch", IEEE Trans. on Antennas and Propagation, vol. 51, no. 6, pp. 1277 - 1280, Jun. 2003

[18] Nasimuddin, X. Qing and Z. N. Chen, "Compact Asymmetric-Slit Microstrip Antennas for Circular Polarization", IEEE Trans. on Antennas and Propagation, vol. 58, no. 12, pp. 3821-3828, Jan. 2011.

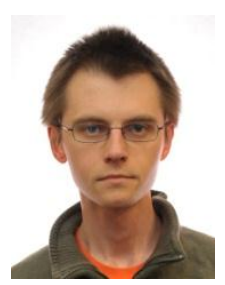

Adam Narbudowicz (S'12) was born in Gdansk, Poland in 1984. He received M.Sc. degree in electronic engineering and telecommunication from Gdansk University of Technology, Gdansk, Poland in 2008. He is currently at Dublin Institute of Technology (DIT), Dublin, Ireland, working towards his Ph.D. degree.

Prior to joining DIT he was involved in research on surrogate modeling of microwave devices at Ghent 
University, Ghent, Belgium. He also participated in Socrates-Erasmus exchange program at University of Karlsruhe, Karlsruhe, Germany. His current research interest include circularly polarized antennas and polarization diversity systems.

Mr. Narbudowicz is recipient of 2012 DIT Inventor Competition Award for the best postgraduate/staff invention.

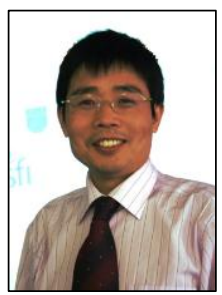

Xiulong Bao (M'09-SM'12) is a Research Fellow with the School of Electronic and Communications Engineering, Dublin Institute of Technology, Ireland. He received the B.Sc. degree in physics from the Huaibei Normal University, Anhui Province, China in July 1991. He was awarded a M.Sc. in Physics and a Ph.D. in Electromagnetic Field and Microwave Technology from Southeast University, Jiangsu Province, China, in April 1996 and April 2003, respectively.

After graduating, he was a Postdoctoral Researcher at Shanghai Jiaotong University, Shanghai, China, before going to Ireland in 2005. His broad research interests include analysis and design of various small and circularly polarized antennas, such as GPS antennas, multiple-band antennas, RFID antennas, a DTV antenna, handset antennas, Ultra Wideband (UWB) antennas and the design and application of metamaterial/EBG structures. He is also active in the study of electromagnetic scattering, electromagnetic numerical computation (FDTD, PSTD, FDFD and MOM methods) and the study of electromagnetic wave propagation and antenna theory. He recently received Science Foundation Ireland funding to research miniaturization techniques for broadband, circularly-polarized antennas. $\mathrm{He}$ has published thirty-five peer-reviewed journal papers and thirty-three conferences articles. He is an IEEE Senior Member and was Technical Program Committee member for the 65th IEEE Vehicular Technology Conference, Dublin, 2007.

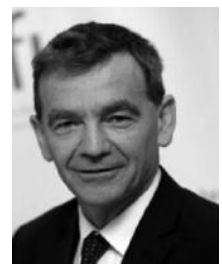

Max Ammann (M'96-SM'08) received the Council of Engineering Institution Part II degree in 1980 and the Ph.D. degree in microwave antenna design from Trinity College, University of Dublin, Dublin, Ireland in 1997.

$\mathrm{He}$ is a Senior Lecturer in the School of Electronic and Communications Engineering, Dublin Institute of Technology, where he is the Director of the Antenna and High Frequency Research Centre. He also leads the antenna research within Ireland's Telecommunications Research Centre (CTVR), Dublin. He spent eight years on radio systems engineering and antenna design for TCL/Philips Radio Communications Systems, Dublin, where he was responsible for commissioning the Nationwide Communications Network for Ireland's national police force. In 1986 he joined the DIT as a Lecturer and was promoted to Senior Lecturer in 2003 and honorary professor in 2012. His research interests broadly include electromagnetic theory, antenna miniaturization for terminal and ultra wideband applications, microstrip antennas, antennas for medical devices and the integration with photovoltaic systems. He has in excess of 200 peerreviewed papers published in journals and international conferences. He has served as an expert to industry on various antenna technologies in the communications, medical, aviation and electronic security sectors in Ireland and abroad. The roles have included design assessment, design solutions, technological strategy reporting and assessment of compliance with international standards on human exposure to electromagnetic energy. The industrial contacts also stem from several successful transfers of fundamental design research into applied solutions.

Dr. Ammann received a best paper award at the 2006 Loughborough Antennas and Propagation Conference, the 2009 SFI best paper award in the China Ireland International Conference in ICT and commercialization awards for work with DecaWave Ltd, Taoglas Ltd and Sequoia Smart Solutions. He also received a 2008 CST University Publication Award for work on a "Wideband Reconfigurable Rolled Planar Monopole Antenna" and a 2011 CST Award for work on "Miniature Ceramic Dual-PIFA Antenna to Support Band Group 1 UWB Functionality in Mobile Handset". He sits on the management committee of the EU COST Action IC1102, "Versatile, Integrated, and Signal-aware Technologies for Antennas (VISTA)" and is active in the EurAAP working group on small antennas. As a member of the IEEE International Committee for Electromagnetic Safety, he participated in the revision of the IEEE Std. C95.1, 2005 \& 2012 standards for Safety Levels with Respect to Human Exposure to Radio Frequency Electromagnetic Fields, $3 \mathrm{kHz}$ to $300 \mathrm{GHz}$. He is also a member of the URSI Committee for Communications and Radio Science within the Royal Irish Academy and official member of URSI Commission K: Electromagnetics in Biology and
Medicine. He has chaired and organized special sessions on small antennas, UWB antennas and UWB Wireless Communication Systems at EuCAP and IEEE APS and chaired the Antennas and Propagation Track for the 65th IEEE VTC, Dublin 2007. He was the local chair for the October 2008 EU COST IC0603 workshop and meeting in Dublin. He is currently associate editor for the IEEE Antennas \& Wireless Propagation Letters. 